\title{
O CONCEITO DE LÍNGUA NA OBRA DE ANTONIO GRAMSCI
}

\author{
Cristiane Lenz
}

Submetido em 28 de maio de 2019.

Aceito para publicação em 06 de julho de 2019.

Cadernos do IL, Porto Alegre, n. ${ }^{\circ}$ 59, outubro. p. 241-254.

POLÍTICA DE DIREITO AUTORAL

Autores que publicam nesta revista concordam com os seguintes termos:

1. Os autores mantêm os direitos autorais e concedem à revista o direito de primeira publicação, com o trabalho simultaneamente licenciado sob a Creative Commons Attribution License, permitindo o compartilhamento do trabalho com reconhecimento da autoria do trabalho e publicação inicial nesta revista.

2. Os autores têm autorização para assumir contratos adicionais separadamente, para distribuição não exclusiva da versão do trabalho publicada nesta revista (ex.: publicar em repositório institucional ou como capítulo de livro), com reconhecimento de autoria e publicação inicial nesta revista.

3. Os autores têm permissão e são estimulados a publicar e distribuir seu trabalho online (ex.: em repositórios institucionais ou na sua página pessoal) a qualquer ponto antes ou durante o processo editorial, já que isso pode gerar alterações produtivas, bem como aumentar o impacto e a citação do trabalho publicado.

4. Os autores estão conscientes de que a revista não se responsabiliza pela solicitação ou pelo pagamento de direitos autorais referentes às imagens incorporadas ao artigo. A obtenção de autorização para a publicação de imagens, de autoria do próprio autor do artigo ou de terceiros, é de responsabilidade do autor. Por esta razão, para todos os artigos que contenham imagens, o autor deve ter uma autorização do uso da imagem, sem qualquer ônus financeiro para os Cadernos do IL.

\section{POLÍTICA DE ACESSO LIVRE}

Esta revista oferece acesso livre imediato ao seu conteúdo, seguindo o princípio de que disponibilizar gratuitamente o conhecimento científico ao público proporciona sua democratização.

http://seer.ufrgs.br/cadernosdoil/index

Terça-feira, 29 de outubro de 2019. 


\title{
O CONCEITO DE LÍNGUA NA OBRA DE ANTONIO GRAMSCI
}

\section{THE CONCEPT OF LANGUAGE IN THE WORK OF ANTONIO GRAMSCI}

\begin{abstract}
Cristiane Lenz ${ }^{*}$
RESUMO: Na primeira metade do século XX, Antonio Gramsci desenvolveu estudos teóricos e filosóficos sobre diversos temas que convergem para a problemática da existência contraditória de forças hegemônicas que atuam sobre as camadas populares da sociedade. Entre eles, o que nos interessa, neste curto espaço, é o seu desenvolvimento das questões que se referem à língua e à gramática. O conceito de nacional-popular prevê a relação necessária da língua com o que é da ordem popular e histórica. Assim, propomos uma reflexão sobre o conceito de língua na obra de Antonio Gramsci, considerando os seus estudos sobre a literatura e a gramática (2002) e a sua tese dos intelectuais orgânicos (1982).
\end{abstract}

PALAVRAS-CHAVE: língua; gramática; história; nacional-popular.

ABSTRACT: In the first half of the twentieth century, Antonio Gramsci developed theoretical and philosophical studies on several themes that converge to the problematic of the contradictory existence of hegemonic forces that act on the popular strata of society. Among them, what interests us in this short space is the development of questions concerning language and grammar. The concept of nationalpopular foresees the necessary relation of the language with what is of the popular and historical order. Thus, we propose a reflection on the concept of language in the work of Antonio Gramsci, considering his studies on literature and grammar (2002) and his thesis of organic intellectuals (1982).

KEYWORDS: language; grammar; history; national-popular.

\section{Introdução}

Os estudos da linguagem que problematizam e discutem a historicidade constitutiva da língua não podem prescindir de partir de questionamentos referentes às relações entre língua e cultura. Tais relações carregam em seu cerne a questão da história nacional e da cultura popular. Alguns estudos do início do século XX elaboram o conceito de língua como identidade nacional ${ }^{1}$ e constituem um importante material de estudo sobre o imaginário nacional de língua e sobre inúmeras questões de ordem semântica, estilística e até mesmo histórica, mas não chegam a uma perspectiva da língua como expressão e representação das forças sociais.

Ainda na primeira metade do século XX, Antonio Gramsci desenvolveu estudos teóricos e filosóficos sobre diversos temas que convergem para a problemática da

\footnotetext{
*Mestra em Letras pela UFRGS. Doutoranda em Letras pela UFRGS. lenzcrys@yahoo.com.br

${ }^{1}$ Um representante desta vertente de estudos é o filósofo e linguista alemão Karl Vossler, que, em suas obras The spirit of language in civilization (1951) ou Filosofia del Lenguaje (1963), desenvolve suas teses da expressão linguística a partir de um sentimento nacional. Além disso, o filósofo italiano Benedetto Croce, a começar pela obra Aesthetic as science of expression and general linguistic (1966), dá luz às discussões sobre estética na língua e nas artes.
} 
existência contraditória de forças hegemônicas que atuam sobre as camadas populares da sociedade. Entre eles, o que nos interessa, neste curto espaço, é o seu desenvolvimento das questões que se referem à língua e à gramática.

Ao dissertar sobre o caráter popular-nacional da língua e da literatura, Gramsci (2002) redimensiona o próprio conceito de "nacional", o que constitui um movimento pioneiro e revolucionário, visto que esses estudos se situam em um período muito próximo ao de outros estudos que, conforme dissemos acima, apresentam um conceito de nacionalismo que não contempla toda a amplitude desse conceito em Gramsci ${ }^{2}$. Essa amplitude é de ordem histórica e parte de uma perspectiva materialista da sociedade, que compreende que a filosofia, para encontrar seu sentido, deve estar sempre em contato com os saberes simples das massas populares (GRAMSCI, 1966). Tal condição provém do conceito gramsciano de filosofia da práxis, que pressupõe a ligação intrínseca entre teoria e prática, entre pensamento e ação. A partir dessa premissa, o filósofo reflete sobre o engendramento e o papel dos intelectuais na sociedade, considerando que, se as forças populares detêm conhecimentos importantes para a compreensão da própria formação da consciência, então a intelectualidade reside de alguma forma em cada esfera da atividade cotidiana (GRAMSCI, 1982). Nesse âmbito, Gramsci chega a sua tese acerca da existência dos processos que dão origem aos intelectuais tradicionais e aos intelectuais orgânicos.

Toda essa construção teórica e filosófica sobre os estratos populares como parte essencial da vida filosófica e intelectual de uma sociedade constitui as bases para a compreensão do conceito de língua como manifestação nacional-popular. A partir disso, Gramsci trata de temas essenciais para a linguística como a transformação da língua, a construção do folclore, a noção de individual e nacional, a relação do povo com a literatura nacional e até mesmo o ensino de gramática, entre outros temas que se situam no escopo da educação.

Partindo dessa perspectiva, objetivamos investigar de que forma o conceito de língua em Gramsci redimensiona a noção de "nacional”. A questão do nacionalismo sob uma perspectiva gramsciana prevê a relação necessária da língua com o que é da ordem popular e histórica. Com vistas a essa relação, propomos uma reflexão sobre o conceito de língua na obra de Antonio Gramsci, em face dos seus estudos sobre a literatura e a gramática (2002), da sua tese dos intelectuais orgânicos (1982), sempre considerando a construção do seu conceito de história (1966).

\section{Dois pontos iniciais de reflexão}

A compreensão de que, para Gramsci, a língua é um objeto de identificação nacional, no qual se representam as forças sociais, a cultura popular e a história de uma nação, deriva de dois pontos principais apresentados a seguir.

O primeiro é que, segundo o autor, a gramática é normativa, mas é também histórica (GRAMSCI, 2002). Ao ser normativa, ela é sempre um ato de política cultural-nacional. Ao ser histórica, ela abarca não só a história nacional, mas a história mundial, agregando contribuições de outras línguas e também elementos que possam criar uma língua nacional comum.

\footnotetext{
${ }^{2}$ Antonio Gramsci esteve na prisão, onde escreveu os Cadernos do Cárcere, entre os anos de 1926 e 1937, sendo o último ano em liberdade condicional e a maior parte deles em Turim (MONASTA, 2010).
} 
O segundo ponto diz respeito a sua concepção de intelectual orgânico, que, diferentemente do intelectual tradicional, se forma no interior das forças sociais e tem o poder de manter ou modificar determinada concepção de mundo. O intelectual tradicional preexiste à formação de um grupo social (GRAMSCI, 1982). Disso, depreendemos que ele não se forma em condições de resistência ou revolução, mas de reprodução das relações de produção, e que o intelectual orgânico seria o verdadeiro agente da transformação de seu próprio modo de vida.

Estes dois aspectos nos chamam a atenção para o fato de que a língua nacional se encontra no nível da infraestrutura e está à mercê das transformações oriundas das forças populares. Além disso, as considerações sobre a normatividade e a historicidade da gramática e a elaboração teórica dos diferentes processos que engendram os grupos de intelectuais em nossa sociedade nos conduzem a refletir sobre questões referentes à construção de um novo conceito de nacionalismo, bem como à definição do que se caracteriza como popular. Em nossa compreensão, esses conceitos são redimensionados na obra de Gramsci.

Tendo delimitado os aspectos a serem estudados, neste momento, na obra de Gramsci, nos dirigimos à leitura e reflexão sobre cada um deles.

\section{A normatividade e a historicidade da gramática}

O Caderno 29, contido no volume 6 dos Cadernos do Cárcere (2002), apresenta uma reflexão sobre a existência e o papel da gramática na língua. A gramática seria o propósito de estabelecer um conformismo linguístico, uma busca pela unificação territorial e identitária. A manifestação da própria tentativa de adequação da linguagem a essa norma gramatical demonstra a condição contraditória do uso da língua por diferentes estratos sociais. $\mathrm{O}$ autor exemplifica essa manifestação através de perguntas como: "O que você entendeu ou quer dizer? Explique-se melhor." (GRAMSCI, 2002, p. 142). Compreendemos então que a busca pela adequação se materializa na forma de metalinguagem. No entanto, essa adequação é regida pela ilusão da unidade linguística e, consequentemente, pressupõe a hegemonia de uma forma em detrimento de outra. Gramsci (2002, p. 142) afirma:

Todo este conjunto de ações e reações conflui no sentido de determinar um conformismo gramatical, isto é, de estabelecer "normas" e juízos de correção e incorreção, etc. Mas esta manifestação desconexa, descontínua, limitada a estratos sociais locais ou a centros locais, etc.

O autor exemplifica essa reflexão através da figura de um camponês que vai para a cidade e faz de tudo para se adequar ao modo de falar urbano, ressaltando que as classes subalternas buscam aproximar sua fala daquela das classes dominantes. Isso nos leva a refletir que o uso da língua em suas especificidades como unidade linguística nacional está diretamente ligado à forma como $\mathrm{o}$ indivíduo compreende $\mathrm{o}$ funcionamento da sociedade em que se insere. Se um indivíduo busca adequar sua linguagem a um ambiente social ou aproximá-la da fala de outros indivíduos, é porque há a percepção de que existe um padrão estipulado, que merece ser seguido, pois tal ambiente ou tais indivíduos apresentam-se, de alguma forma, como o que é bom e legítimo. Assim, estamos diante da existência de uma condição de hegemonia de uma camada social sobre outra. Nesse sentido, Gramsci não faz apenas uma "descrição" do 
que seria a institucionalização da gramática de uma língua nacional, mas nos faz pensar sobre os movimentos que engendram um "conformismo linguístico nacional unitário" (GRAMSCI, 2002, p. 143), o que depreendemos da seguinte reflexão:

\begin{abstract}
As "gramáticas normativas" escritas tendem a abarcar todo um território nacional e todo o "volume linguístico", a fim de criar um conformismo linguístico nacional unitário, o qual, de resto, põe num plano mais elevado o "individualismo" expressivo, já que cria um esqueleto mais robusto e homogêneo para o organismo linguístico nacional, do qual cada indivíduo é o reflexo e o intérprete.
\end{abstract}

Então, a forma de tratamento da gramática de uma língua está sempre vinculada ao modo como uma nação compreende os processos culturais e sociais que se desenrolam em um determinado momento histórico. O modo como o indivíduo percebe quais são os valores hegemônicos que moldam a sociedade em que vive norteia a sua busca $^{3}$ pela adequação à normatização da língua que fala. Disso decorre que há uma repetição e uma reiteração da norma, além, é claro, do fortalecimento de tais valores hegemônicos, na medida em que a língua materializa o constante retorno a um código que confere legitimidade a uma prática.

Atentemos para o seguinte: "A gramática normativa escrita, portanto, pressupõe sempre uma 'escolha', uma orientação cultural, ou seja, é sempre um ato de política cultural-nacional." (GRAMSCI, 2002, p. 144). Gramsci observa que tal "escolha", tal forma de manifestação individual, a partir da ideia que se tem de unidade linguística nacional, é sempre um ato político, ou seja, uma forma de se posicionar a favor de certos interesses que estão sempre condicionados a uma situação social e política e a um momento histórico. A partir disso, o que queremos observar é que essa "escolha", sendo ou não da ordem da consciência das contradições que permeiam e constroem uma sociedade de classes, atesta a existência de valores hegemônicos. Se essas escolhas se materializam na língua, então é ela o instrumento de representação do funcionamento contraditório da sociedade e da própria resistência.

Até agora, falamos da gramática normativa, mas Gramsci observa que, além de ser normativa, a gramática é histórica. A história, para Gramsci (2002), não é apenas a história nacional, mas também mundial. Nenhuma história vive fora do quadro da história mundial. A gramática, por sua vez, ao ser histórica, não tem fronteiras nacionais definidas. Com isso, o autor não só coloca a natureza comparativa das línguas, mas discorre sobre a transformação de uma língua através de inovações linguísticas que ocorrem por influência de outras línguas ${ }^{4}$. É importante, neste momento, refletirmos sobre princípios da concepção de história para Gramsci.

\footnotetext{
${ }^{3}$ É preciso explicitar, aqui, a natureza do tipo de "busca" a qual nos referimos. Em Concepção Dialética da História (1966), Gramsci reflete sobre a filosofia das massas, ou seja, o olhar filosófico que o homem da vida prática, cotidiana, mantém sobre sua existência. A formação de uma consciência crítica dos "simplórios", para empregar o termo usado por Gramsci, é um processo fragmentado e que não acontece da mesma forma que um determinado tipo de intelectual. Essa reflexão é parte da tese sobre os intelectuais orgânicos, que abordaremos mais tarde, mas já aqui depreendemos que essa "busca" por uma adequação à unidade linguística nacional consiste em uma manifestação intelectual, mas não chega a constituir uma verdadeira tomada de consciência sobre as suas condições de existência, ou, nas palavras de Gramsci (1966, p. 21), "a consciência de fazer parte de uma força hegemônica".

${ }^{4}$ Gramsci cita os emigrados repatriados, os viajantes, os leitores de periódicos de língua estrangeira e os tradutores (2002) como meios pelos quais uma língua sofre influência de outra. Sabemos que os Cadernos do Cárcere foram escritos na primeira metade do século XIX. Então, se pensarmos nas
} 
A primeira observação que fazemos sobre esse conceito é que, para Gramsci (1966), a história e a filosofia não são separáveis. Vejamos como esse raciocínio é construído: já nas primeiras páginas de Concepção dialética da história (1966), Gramsci desenvolve a tese de que a filosofia seria uma concepção de mundo, e o agir é sempre pautado por determinada concepção de mundo. Todo homem tem a sua ação prática constituída por uma concepção de mundo. Então, a sua conduta é, de certa forma, uma atividade filosófica. Logo, o estudo da história das diversas filosofias dos filósofos não é suficiente porque não contempla a história da existência prática, mas apenas de um grupo de intelectuais. A filosofia de uma época, em sua ampla compreensão, engloba necessariamente os elementos filosóficos e as concepções de mundo não só de diferentes grupos de intelectuais, mas também de diferentes parcelas das massas populares. Com esse raciocínio, leiamos sua tese sobre a aproximação da história e da filosofia:

A filosofia de uma época histórica, portanto, não é senão a "história" desta mesma época, não é senão a massa de variações que o grupo dirigente conseguiu determinar na realidade precedente: neste sentido, história e filosofia são inseparáveis, formam um "bloco". (GRAMSCI, 1966, p. 32)

Observamos, sob esse prisma, o caráter materialista do conceito gramsciano de história, visto que o olhar sobre as relações entre as massas populares e as classes dirigentes constitui um fator decisivo para a compreensão da forma como concepções de mundo distintas atuam em diferentes momentos históricos no funcionamento de uma nação.

Gramsci observa a consciência da historicidade como uma condição para o conhecimento dos problemas de um tempo presente. Essa historicidade contempla não um relato de fatos mecanicista, mas o conhecimento de como uma sociedade se desenvolveu filosoficamente e na relação de sua nação com outras nações. Segundo o autor (1966), não podemos ter uma concepção de mundo criticamente coerente sem a consciência sobre a história do pensamento filosófico ou a história da cultura. Esses dois aspectos são, conforme refletimos acima, a história em si mesma, pois não há filosofia, concepção de mundo ou movimento cultural que exista sem seu vínculo com a prática cotidiana e até mesmo sua origem no interior desta. Claro, a tese marxista ${ }^{5}$ nos ensina que a história é a história das condições materiais de existência, e, por conseguinte, da constituição de um modo de produção. Compreendemos que essa tese se encontra no cerne do conceito gramsciano de história. Contudo, Gramsci lida também com questões concernentes à construção filosófica e cultural, e o faz sob a premissa marxista de que não há filosofia que se suporte sem a observação da práxis, ou seja, a prática cotidiana e material. Isso constitui o movimento dialético da unicidade da teoria

inovações linguísticas hoje, partindo da concepção gramsciana de história mundial, consideraremos a tecnologia como um dos principais meios de disseminação dessas inovações. De qualquer forma, essa reflexão parece residir somente no âmbito físico da transformação da língua, e não nos processos que a engendram. Seria preciso considerar os fatores econômicos, ao lado de movimentos culturais e sociais, para compreender fatos como a inserção de palavras estrangeiras em um idioma.

${ }_{5}^{5}$ As bases para esta reflexão podem ser encontradas na Ideologia alemã (2007). Nesta obra, Marx e Engels discorrem sobre a contradição e a ideologia de uma sociedade regida por determinado modo de produção. Os autores mostram que as relações materiais são a base para as demais relações humanas e que a história é uma sucessão de diferentes gerações que explora o capital e as forças de produção deixadas pelas relações que a precederam. 
e da prática. Com essa reflexão, chegamos à compreensão de como se engendra a concepção dialética de história de Gramsci.

É necessário pensar, todavia, quais as implicações de uma perspectiva dialética da história. Primeiramente, pensar sob o prisma do pensamento filosófico como um pensamento que deriva da atividade prática do homem, ou seja, sob o prisma da filosofia da práxis, implica considerar as forças populares como o lugar dos agentes da história e da transformação. Assim, a infraestrutura apresenta-se como o lugar de construção de concepções de mundo próprias a ela. Esse lugar é notavelmente contraditório, uma vez que abriga a reprodução e também a resistência aos valores hegemônicos, ou seja, uma concepção de mundo própria da infraestrutura se constitui na relação e no embate com outras concepções de mundo superestruturais ${ }^{6}$.

Outra implicação decorrente da tomada do conceito de história pelo prisma da filosofia da práxis é a dimensão que o próprio conceito de nação adquire. Na medida em que as camadas populares fazem parte da construção filosófica de uma sociedade, cultura e concepção de mundo não são conceitos unilaterais ou homogêneos. Assim, a nação não se constitui como uma unidade, e sim como um todo fragmentado e heterogêneo. Além disso, se considerarmos, como refletimos anteriormente, que há o embate entre estratos populares e forças hegemônicas, então a nação se constrói também de forma não só heterogênea, mas contraditória.

Nesse sentido, a língua nacional também não é unitária e comum a todos os indivíduos que compõem uma nação. A língua como objeto de representação de concepções de mundo está sujeita à própria diversidade de cultura e do pensamento de um grupo de indivíduos de uma nação. Esse fato é previsto por Gramsci (2002, p. 144, grifo nosso), quando ele afirma o seguinte:

Se se parte do pressuposto de centralizar o que já existe em estado difuso, disseminado, mas inorgânico e incoerente, parece que não é racional uma oposição de princípio; cabe, ao contrário, uma colaboração de fato e uma cuidadosa acolhida de tudo o que possa servir para criar uma língua comum nacional, cuja inexistência determina atritos sobretudo nas massas populares $[\ldots]$.

É importante ressaltar que Gramsci (1966, p. 13) compreende que "a língua contém os elementos de uma concepção de mundo e de uma cultura". Isso implica que é pela língua que se verifica a complexidade da concepção de mundo de um grupo ou indivíduo. Ou seja, a língua é a materialização do pensamento e da cultura. Se a concepção de mundo é tão diversa quanto o é a nação em termos de estratos e realidades socioeconômicas, então a língua apresenta-se em uma multiplicidade de formas e sentidos.

Gramsci também observa que é inadequado analisar a língua sob a ótica de pressupostos artísticos, porque essa perspectiva coloca limites históricos, visto que, nesse caso, a língua seria apenas material da arte, e não uma representação histórica por si só. Atentemos para a seguinte passagem:

A história das línguas é história das inovações linguísticas, mas estas inovações não são individuais (como ocorre na arte): são de toda uma comunidade social que inovou sua cultura, que "progrediu" historicamente.

\footnotetext{
${ }^{6}$ Essa reflexão encontra respaldo, principalmente, na tese dos intelectuais orgânicos, da qual trataremos mais adiante.
} 
Naturalmente, elas se tornam individuais, mas não do indivíduo-artista, e sim do indivíduo elemento histórico-cultural completo, determinado. (GRAMSCI, 2002, p. 197, grifo do autor)

Com base nessas afirmações, compreendemos a necessidade de pensar a língua como elemento crucial para compreender a história de uma nação, sempre com vistas à história mundial. A língua não é material de apoio para que a arte se construa em seu poder de representação. Ela é, ao mesmo tempo, o elemento de representação histórica e de transformação de uma ordem social.

\section{A tese sobre os intelectuais orgânicos}

A tese gramsciana sobre os intelectuais orgânicos é, ao mesmo tempo, o início e o cerne para compreender o papel das camadas populares na construção filosófica de uma sociedade.

Gramsci (1982) expõe que há dois processos mais importantes no que diz respeito à formação das camadas intelectuais. O primeiro origina-se no terreno da produção econômica, a partir de relações com outras camadas intelectuais que conferem consciência sobre sua própria função no interior dessa produção. Compreendemos que desse grupo originam-se os denominados intelectuais orgânicos. O próprio termo já diz respeito à constituição da intelectualidade no interior da organização social e na relação entre os órgãos que constituem determinada sociedade. Atentemos para a seguinte reflexão:

\footnotetext{
Não existe atividade humana da qual se pode separar o homo faber do homo sapiens. Em suma, todo homem, fora de sua profissão, desenvolve uma atividade intelectual qualquer, ou seja, é um "filósofo", um artista, um homem de gosto, participa de uma concepção de mundo, possui uma linha consciente de conduta moral, contribui assim para manter ou para modificar uma concepção do mundo, isto é, para promover novas maneiras de pensar. (GRAMSCI, 1982, p. 7-8, grifo do autor)
}

Nesse processo, o que coloca condições para a elaboração de uma concepção de mundo é a própria prática cotidiana, as funções do trabalho, enfim, as ações que asseguram a existência material. Essa concepção de mundo é uma prática intelectual e filosófica na medida em que qualquer ação de natureza prática pressupõe um modo de relação com a realidade social e cultural, ou seja, pressupõe uma linha de conduta conforme destacou Gramsci no excerto acima. No interior da prática profissional, originam-se especialistas em funções diversas, que contribuem para o desenvolvimento de determinada parte do conhecimento e da evolução de um "mercado" de bens, serviços ou tecnologias. Dessa função prática e especializada não deriva apenas um afazer técnico, mas também um conjunto de princípios que conduzem a prática social e cultural. Compreendemos que, nesta reflexão, podemos melhor definir o conceito de "concepção de mundo" sobre o qual nos fala Gramsci, ou seja, o conjunto de princípios que norteiam a vida social e cultural, que se origina nas funções práticas da existência material e, ao mesmo tempo, incide sobre ela mesma.

Propomos a seguinte reflexão: se o engendramento dos princípios que norteiam a vida social e cultural está nas práticas da existência material, então a concepção de mundo de um grupo de indivíduos não existe senão em um vínculo estreito com as suas 
relações com o trabalho e com as ações que asseguram as condições materiais de existência. Dessa forma, a relação de um indivíduo com o trabalho conduz as suas condições de existência, não só materiais, mas sociais e culturais. Em última instância, essa relação produz a sua concepção de mundo ${ }^{7}$.

Falemos agora no segundo processo apontado por Gramsci (1982) como responsável pela formação de categorias intelectuais. Esse processo diz respeito a um grupo que surge a partir da estrutura econômica que o precede historicamente, carregando consigo o próprio desenvolvimento dessa estrutura. Esse grupo representa uma continuidade dos princípios e formas de pensamento ao longo da história. Eles estão vinculados a uma organização social ou instituição e desempenham a função de "intelectuais", sendo que o fazem de acordo com os interesses e as concepções da organização na qual se inserem. Contraditoriamente, "eles consideram a si mesmos como sendo autônomos e independentes do grupo social dominante." (GRAMSCI, 1982, p. 6). É o caso, por exemplo, dos eclesiásticos. Se refletirmos brevemente, no entanto, veremos que o grupo pertencente às instituições religiosas não só não é independente do grupo social dominante, como também faz parte de uma organização dominante que dita princípios e valores. Tais princípios e valores repercutem, primeiramente, na vida moral de uma sociedade, para, a partir daí, conduzir as relações econômicas entre indivíduos e instituições.

Uma afirmação importante para a compreensão do papel dessa categoria de intelectuais é a seguinte:

\begin{abstract}
Os intelectuais são os "comissários" do grupo dominante para o exercício das funções subalternas da hegemonia social e do governo político, isto é: 1) do consenso "espontâneo" dado pelas grandes massas da população à orientação impressa pelo grupo fundamental dominante à vida social, consenso que nasce "historicamente" do prestígio [...] que o grupo dominante obtém, por causa da sua posição e de sua função no mundo da produção; 2) do aparato da coerção estatal que assegura "legalmente" a disciplina dos grupos que não “consentem", nem ativa nem passivamente, mas que é constituído para toda a sociedade, na previsão dos momentos de crise no comando e na direção, nos quais fracassa o consenso espontâneo. (GRAMSCI, 1982, p. 11)
\end{abstract}

Compreendemos, então, que esse grupo de intelectuais exerce, historicamente, uma função de disposição e, mesmo, imposição, de valores hegemônicos. Chama-nos a atenção a reflexão de que a própria função e a posição no interior da produção ocupadas pelo grupo dominante faz com que ele obtenha uma condição de prestígio. Disso depreendemos que tanto a superestrutura quanto a infraestrutura se constroem a partir de valores hegemônicos na medida em que os reconhecem como legítimos por serem difundidos por essa classe dirigente de intelectuais. Estes, por sua vez, são reconhecidos como detentores de um poder "legítimo" justamente por ocuparem determinada posição no modo de produção, mais especificamente, uma posição de destaque em uma hierarquia capitalista ou uma função que favoreça as demandas dessa hierarquia.

Agora, tendo apresentado os dois processos que dão origem às camadas intelectuais, segundo Gramsci (1982, p. 11), é preciso refletir sobre quais são as implicações de se considerar, por um lado, que a própria atividade de produção

\footnotetext{
${ }^{7}$ Tal reflexão poderia se desenvolver no âmbito da divisão do trabalho. Na medida em que a relação dos indivíduos com o trabalho está na origem dos processos que engendram as concepções de mundo de um grupo, a própria divisão do trabalho é determinante na produção dos princípios que norteiam as condições de existência de uma comunidade.
} 
econômica dá origem a um tipo de intelectual e, por outro, que há uma camada intelectual que promove a continuidade histórica de valores e de uma "disciplina".

Se o intelectual orgânico tem sua origem nos processos de produção econômica, então ele se forma no interior das forças sociais, a partir da sua própria perspectiva sobre as relações de produção. Isso aponta para duas reflexões. A primeira é que a sua atividade intelectual, ou seja, a sua ação prática com vistas às suas concepções de mundo depende da forma como ele se relaciona com as condições que determinam suas relações de trabalho. Nesse caso, haverá, em primeira instância, a reprodução ${ }^{8}$ dessas condições, e, dependendo de fatores históricos, haverá um grau maior ou menor de resistência e transformação.

A segunda reflexão é que o intelectual orgânico, ao se formar no interior das forças sociais, está em uma posição de intervenção na sua realidade social. Nesse sentido, a tese de Gramsci é revolucionária na medida em que ele confere às massas o lugar de agentes da transformação do seu próprio modo de vida. Enquanto os intelectuais tradicionais têm a função de dar continuidade aos princípios de um modo de produção, os intelectuais orgânicos estão em posição de resistir e transformar.

Outra implicação da teoria sobre os intelectuais orgânicos é que ela incide sobre o próprio conceito dialético de história de Gramsci. Para compreender a transformação e a resistência no interior de uma formação social, é preciso olhar para o papel dos intelectuais orgânicos, visto que os intelectuais tradicionais são forças que trabalham para a repetibilidade. A ação dos intelectuais orgânicos se dá a partir de suas concepções de mundo, ou seja, a partir de uma atividade filosófica, conforme já explicitamos. Então, essa ação acontece na relação dialética da teoria e da prática, e na contestação ${ }^{9}$ dos valores hegemônicos. Nesse sentido, a história acontece sob o prisma da dialética, na relação contraditória entre superestrutura e infraestrutura. Assim, se os intelectuais orgânicos são reconhecidos como categoria intelectual, logo as massas são agentes da história, ou seja, a história se constrói na contradição dos interesses antagônicos, mas a prática da transformação reside primordialmente na infraestrutura como representação das forças sociais.

\section{A língua e o conceito de nacional-popular}

A leitura sobre a normatividade da gramática e sobre os processos que originam os intelectuais tradicionais e os intelectuais orgânicos, bem como o papel destes na

\footnotetext{
${ }^{8}$ É preciso esclarecer que, nesse sentido, trabalhamos com o conceito althusseriano de reprodução, que nos auxilia a compreender que a reprodução se desenvolve no âmbito contraditório da luta de classes, e que, por isso, pressupõe sempre algum nível de transformação. "[...] a reprodução da ideologia dominante não é a simples repetição, não é uma simples reprodução, nem tampouco uma reprodução ampliada, automática, mecânica de determinadas instituições, definidas, de uma vez para sempre, por suas funções, mas o combate pela reunificação e a renovação e elementos ideológicos anteriores, desconexos e contraditórios, em uma unidade conquistada na e pela luta de classes, contra as formas anteriores e as novas tendências antagônicas. A luta pela reprodução da ideologia dominante é um combate inacabado que deve ser sempre retomado e está sempre submetido à lei da luta de classes." (ALTHUSSER, 2008, p. 240, grifos do autor).

9 É preciso esclarecer que essa "contestação" não é, necessariamente, da ordem da consciência da luta de classes, mas ela se engendra nas condições materiais de existência e nas próprias necessidades de ordem cotidiana.
} 
sociedade, permite-nos pensar sobre a dimensão que o conceito de nacionalismo toma na teoria gramsciana.

Partimos da reflexão de Brandist $^{10}$ (2012), que faz uma ampla leitura das relações entre língua e hegemonia na obra de Gramsci. O autor chama a atenção para o debate no Caderno 29 de Cadernos do Cárcere sobre a necessidade emergente, no contexto das primeiras décadas do século XX da União Soviética, de uma língua que proporcionasse compreensão e diálogo entre as massas e a política, ou seja, uma língua com função social. Leiamos a seguinte passagem:

By the mid-1920s a series of competing solutions were being formulated, ranging from the propagation of the language of the pre-revolutionary classics [...], through investing the colloquial language with wider social functions and encouraging the emergence of a standard that was close to that spoken by the masses [...], drawing on the linguistic creativity of the enfranchised masses to renew the public discourse and make it into a medium of enlightenment. (BRANDIST, 2012, p. 32) ${ }^{11}$

Nesse sentido, compreendemos que é no contexto revolucionário soviético que surgem as condições para a discussão acerca da relação entre língua e hegemonia, e língua como possibilidade de emancipação e poder das massas. A própria criatividade das massas seria uma condição para a renovação e transformação das formas vernaculares. Continuemos a reflexão com Brandist (2012, p. 32):

This was precisely a debate about the relationship between what in Notebook 29 Gramsci was to call normative and spontaneous or immanent grammars [...]: was the former to be imposed on the latter, or was a new norm to emerge from the interactions between spontaneous grammars? It also, crucially, raised the issue of the role of intellectuals in this process: of the traditional intellectuals inherited from pre-revolutionary times, and of the organic intellectuals that arose from the workers and peasants themselves. ${ }^{12}$

O autor destaca que os intelectuais orgânicos compunham a organização da imprensa popular soviética e eram o meio de comunicação entre o estado e as massas. Sobre essa comunicação, Brandist (2012, p. 32-33) destaca:

Here, language was by no means simply a technical medium, but the embodiment and articulation of socio-specific world views, and the attention of many Party leaders, including Trotsky [...] and Bukharin [...], were

\footnotetext{
${ }^{10}$ Dr. Craig Brandist é professor no departamento de Estudos Russos e Eslavos na Universidade de Sheffield. Sua pesquisa contempla, entre outros temas no interior dos estudos da História das Ideias, a história do desenvolvimento cultural na Rússia.

${ }^{11}$ Tradução sob responsabilidade da autora: "Na metade da década de 1920, uma série de soluções concorrentes estavam sendo formuladas, variando desde a propagação da linguagem dos clássicos prérevolucionários [...], através de uma proposta de uso da linguagem coloquial com funções sociais mais amplas e do incentivo ao surgimento de um padrão mais próximo daquele falado pelas massas [...], aproveitando a criatividade linguística das massas emancipadas para renovar o discurso público e transformá-lo num meio de conhecimento.”.

${ }^{12}$ Tradução sob responsabilidade da autora: "Este foi precisamente um debate sobre a relação entre o que no Caderno 29 Gramsci chamaria de gramática normativa e espontânea ou imanente [...]: seria o primeiro imposto sobre o último, ou seria uma nova norma a emergir das interações entre gramáticas espontâneas? Isso também, crucialmente, levantou a questão do papel dos intelectuais nesse processo: dos intelectuais tradicionais herdados dos tempos pré-revolucionários e dos intelectuais orgânicos que surgiram dos próprios trabalhadores e camponeses.".
} 
concerned with delicate balance between the need to adjust the language of the press to the needs of the masses, and the need to raise the verbal skills of the masses. ${ }^{13}$

Compreendemos, assim, a existência de uma preocupação crescente sobre a necessidade de uma língua que pudesse servir aos interesses das massas, que pudesse proporcionar esclarecimento e diálogo com a imprensa. Em seus escritos, Gramsci observa essa preocupação e tece comparações com o contexto social, político e cultural italiano.

Ao longo do volume 6 de Cadernos do Cárcere (2002), Gramsci discorre sobre questões relacionadas à literatura nacional de diferentes países para refletir sobre a relação do povo com a literatura e com a expressão cultural. Ao levantar essas questões, o autor aproxima a expressão cultural do que seria a expressão popular.

$\mathrm{O}$ autor reflete sobre como a arte e a literatura podem constituir forças de expressão popular, sob a condição de que o conteúdo moral e intelectual seja a elaboração das aspirações da nação num certo momento de seu desenvolvimento histórico (GRAMSCI, 2002, p. 39). Nesse sentido, o conceito de nacional-popular está atrelado à história de uma nação. Se o conceito gramsciano de história é dialético, então há a caracterização do que é da ordem do nacional e do popular como contraditório e heterogêneo. Assim, o nacionalismo não remete a uma unidade ou ao sentimento de pertencimento a uma nação unitária, mas à consciência dos indivíduos como partes de uma totalidade, de uma sociedade que vive sob a determinação de forças contraditórias. Ademais, a expressão popular constitui uma força de representação do desenvolvimento histórico de uma nação, das massas e de suas lutas e demandas.

Além disso, Gramsci desconstrói a ideia de unidade nacional ao observar que os intelectuais - os tradicionais, conforme compreendemos - estão distantes do povo e não estão ligados a ele por temáticas de interesse popular. Leiamos o seguinte excerto:

\begin{abstract}
Os intelectuais não saem do povo, ainda que acidentalmente algum deles seja de origem popular; não se sentem ligados ao povo (à parte a retórica), não o conhecem e não sentem suas necessidades, suas aspirações e seus sentimentos difusos; mas são, em face do povo, algo destacado, solto no ar, ou seja, uma casta e não uma articulação (com funções orgânicas) do próprio povo. A questão deve ser estendida a toda a cultura nacional-popular e não se restringir apenas à literatura narrativa [...]. (GRAMSCI, 2002, p. 43)
\end{abstract}

É preciso observar que essa reflexão de Gramsci se dá a partir da observação da falta de alcance da produção intelectual no interior da cultura popular italiana. No entanto, ao partir de uma observação do contexto de sua própria nação, Gramsci desenvolve um conceito de nacionalismo que transcende o idealismo de pensar na nação como um todo homogêneo, com uma cultura oficial e monopolizada pelo cânone. Ao contrário disso, o que é da ordem do nacional está primordialmente vinculado ao que pertence ao domínio popular, o que entendemos como sendo do domínio das forças sociais. Assim, a própria definição de "popular" toma uma dimensão ampla, conferindo a esse adjetivo a força de ser a perspectiva mais importante na caracterização da cultura nacional.

\footnotetext{
13 Tradução sob responsabilidade da autora: “Aqui, a língua não era, de modo algum, simplesmente um meio técnico, mas a encarnação e a articulação das visões do mundo socioespecíficas, e a atenção de muitos líderes do Partido, incluindo Trotsky [...] e Bukharin [...], estavam preocupados com o equilíbrio delicado entre a necessidade de ajustar o idioma da imprensa às necessidades das massas e a necessidade de elevar as habilidades verbais das massas.”.
} 


\section{Considerações finais}

A obra de Antonio Gramsci é extensa, ampla e, às vezes, um tanto fragmentada, como, por exemplo, as teses contidas nos "cadernos miscelâneos". Por outro lado, o autor é incisivo em suas colocações, e não só desconstrói, mas também reconstrói, o que nos permite verificar a própria ciência dialética a serviço da transformação de conceitos e da abertura a novas perspectivas sobre diferentes temas, entre eles, a língua, a gramática e suas implicações no âmbito da caracterização do que constitui o nacional e o popular.

O materialismo histórico e dialético está no cerne de toda tese gramsciana, e a sua leitura vem a corroborar e destacar a necessidade de uma abordagem materialista da língua. $\mathrm{O}$ fato de partir de uma concepção material da língua abre caminho para uma nova compreensão sobre os processos culturais na sociedade, e isso produz um deslocamento de forças na medida em que confere às forças sociais um papel de destaque como agentes de transformação. Uma concepção material de língua trabalha lado a lado com a história e compreende a língua como força de representação e de transformação social. Esse ponto de partida é capaz de reformular o próprio ensino de língua materna, transformar a relação das massas com a língua nacional e, assim, revolucionar as formas de relação do indivíduo com o estado e com a política.

\section{REFERÊNCIAS}

ALTHUSSER, Louis. Sobre a reprodução. Petrópolis: Vozes, 2008.

BRANDIST, Craig. The cultural and linguistic dimensions of hegemony: aspects of Gramsci's debt to early Soviet cultural policy. Journal of Romance Studies, v. 12, n. 3, p. 24-43, 2012.

CROCE, Benedetto. Aesthetic as science of expression and general linguistic. New York: Noonday Press Edition, 1966.

GRAMSCI, Antonio. Concepção dialética da história. Rio de Janeiro: Civilização Brasileira, 1966.

. Os intelectuais e a organização da cultura. Rio de Janeiro: Civilização Brasileira, 1982.

Cadernos do cárcere. v. 6. Rio de Janeiro: Civilização Brasileira, 2002.

MARX, Karl; ENGELS, Friedrich. A ideologia alemã. Rio de Janeiro: Civilização Brasileira, 2007.

MONASTA, Attilio. Antonio Gramsci. Recife: Massangana, 2010.

VOSSLER, Karl. The spirit of language in civilization. London: Kegan Paul, 1951. 
Filosofia del lenguaje. Buenos Aires: Editorial Losada, 1963. 